\title{
MODIFIKASI MOTOR BRUSHLESS DC MENJADI GENERATOR SINKRON MAGNET PERMANEN FLUKS RADIAL PUTARAN RENDAH
}

\author{
Dhea Gemilang Ramdhany ${ }^{1}$, Nurul Hiron ${ }^{2}$, Nundang Busaeri ${ }^{3}$ \\ Teknik Elektro, Fakultas Teknik, Universitas Siliwangi, Tasikmalaya, Indonesia ${ }^{1,2,3}$
} Email: dheagemilang27@gmail.com ${ }^{1}$

\begin{abstract}
Research on power generation continues to grow along with the increasing demand for electrical energy. Utilization of renewable energy sources such as wind power, hydro power, ocean wave power and ocean current power requires a low-speed electric generator without additional excitation to produce electrical energy. Permanent magnet synchronous generator (PMSG) is a generator whose excitation field is generated by a permanent magnetic field. This generator has the advantage of being able to operate at low and high rotations and has a better level of efficiency compared to induction generators. The use of PMSG can be obtained by utilizing the BLDC motor of a used single-tube washing machine. The specifications for the outer rotor type BLDC motor have a stator coil in the form of an iron-core gear, totaling 36 coils with $1 \times 12$ 3-phase coil wiring, consisting of 90 turns per coil with a wire cross-sectional diameter of 0.8 mm, made of aluminum with concentrated winding type. The rotor has 12 permanent magnet rods made of Barium ferrite (BaO 6Fe2O3). The construction of the BLDC and PMSG motors has a similarity where the rotor has a permanent magnet, so that the BLDC motor can be considered to be applied as a generator. The test results of the BLDC generator can generate 855 VA of electric power at a rotational speed of 1300 RPM, the working voltage of the generator is 200 VAC neutral-phase, 350 VAC phases with an efficiency of $68.2 \%$.
\end{abstract}

Keywords: Permanent magnet synchronous generator (PMSG), BLDC motor, power plant.

\begin{abstract}
Abstrak
Penelitian pembangkit listrik terus berkembang seiring meningkatnya kebutuhan energi listrik. Pemanfaatan sumber energi terbarukan seperti tenaga angin, tenaga air, tenaga gelombang laut serta tenaga arus laut memerlukan generator listrik putaran rendah tanpa eksitasi tambahan untuk dapat menghasilkan energi listrik. Generator sinkron magnet permanen (PMSG) merupakan generator yang medan eksitasinya dihasilkan oleh medan magnet permanen. Generator ini memiliki keunggulan dapat beroperasi pada putaran rendah serta tinggi memiliki tingkatan efisiensi yang lebih baik dibanding dengan generator induksi. Penggunaan PMSG bisa didapat dengan memanfaatkan motor BLDC mesin cuci bekas tipe satu tabung. Spesifikasi motor BLDC tipe outer rotor memiliki kumparan stator berbentuk roda gigi berinti besi berjumlah 36 coil dengan wiring 1 x 12 coil 3 fasa, terdiri 90 lilitan tiap coil dengan diameter penampang kawat 0,8 mm, berbahan alumunium dengan jenis belitan concentrated. Rotor memiliki 12 batang magnet permanen berbahan Barium ferrite (BaO 6Fe2O3). Secara konstruksi motor BLDC dan PMSG memiliki sebuah kemiripan dimana pada bagian rotornya terdapat magnet permanen, sehingga motor BLDC dapat dipertimbangkan untuk diaplikasikan sebagai generator. Hasil pengujian generator dari BLDC dapat membangkitkan daya listrik sebesar 855 VA pada kecepatan putar 1300 RPM, tegangan kerja generator sebesar 200 VAC fasa-netral, 350 VAC fasa-fasa dengan efisiensi sebesar $68,2 \%$
\end{abstract}

Kata Kunci: Generator sinkron magnet permanen (PMSG), motor BLDC, pembangkit listrik.

\section{PENDAhUluan}

Generator listrik merupakan suatu alat yang digunakan untuk mengubah energi mekanik menjadi energi listrik yang berbasis pada induksi magnet. Prinsip kerja dari generator sesuai hukum faraday ialah elektromagnetisme hubungan antara perubahan medan magnet terhadap suatu kumparan yang menciptakan Gaya Gerak Listrik [1].

Generator sinkron magnet permanen (PMSG) ialah mesin listrik berputar dengan tiga fasa stator klasik semacam generator induksi pada umumnya. Magnet permanen dapat terpasang pada permukaan maupun tertanam pada rotornya. Generator dengan magnet permanen memiliki tingkatan efisiensi yang lebih baik dibanding dengan generator induksi, sebab tidak terdapat rugi-rugi eksitasi yang dihasilkan [2].

Penggunaan generator sinkron magnet permanen (PMSG) selain beli dipasaran bisa juga dengan memodifikasi motor BLDC mesin cuci bekas. Mesin cuci yang digunakan berjenis satu tabung. Bentuk stator yang digunakan seperti roda gigi berjumlah 36 coil dengan formasi kumparan 1 x 12 coil tipe belitan satu lapis (Concentrated Windings). Motor BLDC berjenis Outer Rotor dengan magnet permanen berjumlah 12 buah menempel secara radial dipermukaan bagian dalam plat roda, sehingga medan magnet yang dihasilkan akan menginduksi kumparan secara terpusat. [3].

Secara konstruksi mesin BLDC dan PMSG memiliki sebuah kemiripan dimana pada bagian rotornya terdapat magnet permanen, sehingga motor BLDC dapat dipertimbangkan untuk diaplikasikan sebagai generator. Modifikasi yang dilakukan berfokus pada sistem induksi kumparan yaitu merubah formasi kumparan stator 1 x 12 coil menjadi $6 \times 2$ coil dengan dipengaruhi kecepatan putaran rotor [4].

Berdasarkan masalah diatas, penulis ingin merancang PMSG fluks radial menggunakan motor BLDC mesin cuci bekas. Untuk mengetahui karakteristik PMSG fluks radial ini maka dilakukan identifikasi formasi kumparan pabrik 1 x 12 coil dengan formasi kumparan yang telah dimodifikasi menjadi 6 x 2 coil, batas tegangan kerja pada 115 VAC - 200 VAC pada pengujian open circuit, pengujian short circuit dan pengujian full load dengan variasi kecepatan (250, 500, 750, 1000, 1250 dan 1400) RPM yang dikendalikan menggunakan PWM [5]. 


\section{KAJIAN PUSTAKA}

\subsection{Motor BLDC}

Motor BLDC bekerja dengan menggunakan prinsip gaya tarik antara dua magnet yang berlainan kutub atau gaya tolak antara dua magnet dengan kutub yang sama. Rotor pada motor BLDC tersusun dari magnet permanen sehingga kutubnya tetap sedangkan stator terbuat dari belitan sehingga kutub magnet tersebut dapat berubah tergantung polaritas arus belitan stator yang diberikan [6].

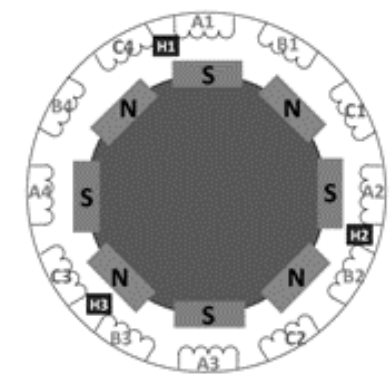

Gbr 1. Konstruksi BLDC

\subsection{Generator Sinkron Magnet Permanen}

Generator sinkron magnet permanen merupakan generator yang medan eksitasinya dihasilkan oleh magnet permanen. Magnet permanen menghasilkan fluks sehingga arah garis-garis gaya magnet keluar dari kutub magnet secara radial atau axial. Generator ini memiliki konstruksi umum yaitu kumparan stator sebagai tempat terjadinya induksi elektromagnetik, rotor tempat tertanamnya magnet permanen sebagai sumber medan magnet, dan celah udara sebagai tempat mengalirnya fluks udara dari rotor ke stator. [7].

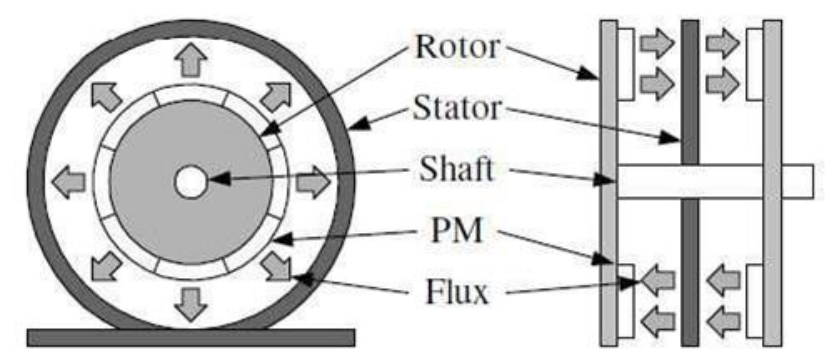

\subsection{Prinsip Kerja Generator}

Gbr 2. Konstruksi PMSG

Hukum faraday menyatakan bahwa jika fluks melewati perubahan kumparan kawat, tegangan akan diinduksi pada pergantian kawat yang langsung sebanding dengan tingkat perubahan fluks sehubungan dengan waktu [8].

$$
\operatorname{Ein}=-N \frac{d \Phi}{d t}
$$

\subsection{Tegangan Induksi Yang Dibangkitkan}

$$
\text { Erms }=\frac{E m a k s}{\sqrt{2}}=\frac{2 \pi}{\sqrt{2}} \times \mathrm{N} \times f \times \Phi \text { maks } \times \frac{N s}{N p h}
$$

\subsection{Frekuensi Elektris}

Frekuensi elektris yang dihasilkan oleh generator sinkron adalah serempak dengan kecepatan putar generator [9].

$$
f=\frac{N r \cdot P}{120}
$$

2.6 Torsi Generator

$$
\begin{aligned}
& \omega=\frac{n \cdot 2 \cdot \pi}{60} \\
& K=\frac{\text { Vac }}{\omega}, \text { dimana } K t=K e \\
& T=K t . I
\end{aligned}
$$

2.7 Daya Generator

Daya generator dihitung dengan memasukan nilai parameter yang telah ditentukan.

$$
P=D 2 L(0.5 \pi 2) K w N s B g a c \cos \theta
$$

\subsection{Arus Generator}

Arus pada generator dapat dicari setelah daya pada generator diketahui serta nilai tegangan telah ditentukan.

$$
I L=\frac{\text { Pout }}{\sqrt{3 \cdot \mathrm{m} \cdot \mathrm{Vt}}}
$$

\subsection{Fluks Magnet}

Fluks magnet mengalir dari kutub utara magnet melewati celah udara dan stator lalu menuju ke kutub selatan magnet. Langkah pertama untuk menghitung fluks magnet yaitu dengan mengitung luas kutub magnet tersebut[10].

$$
\begin{gathered}
K r=\pi d r \\
K r i \%=\frac{\pi \mathrm{dr}-\mathrm{df} \mathrm{Ndf}}{\pi \mathrm{dr}} \times 100 \% \\
A m=(p m \cdot w m) 2 \cdot K r i \%
\end{gathered}
$$

2.10 Medan Magnet

$$
\begin{aligned}
& B_{\text {maks }}=B r \frac{\mathrm{lm}}{\operatorname{lm}+\delta} \\
& \Phi=A m \cdot B \text { maks }
\end{aligned}
$$

2.11 Penentuan Jumlah Lilitan

$$
N C=\frac{\text { Erms }}{4,44 \cdot \mathrm{f} \cdot \Phi \frac{N s}{N p h}}
$$

\subsection{Efisiensi}

$$
\eta=P O u t / P \operatorname{In} \times 100 \%
$$

2.13 Regulasi Tegangan

$$
\text { Vreg }=\frac{\text { VAC no load }- \text { VAC load }}{\text { VACload }} \times 100 \%
$$

\subsection{Persamaan Regresi Kuadratik}

Pengaruh kecepatan putaran terhadap tegangan yang dihasilkan dapat diestimasi dengan persamaan regresi kuadratik[11].

$$
\begin{array}{r}
\hat{\mathrm{Y}}=\mathrm{b}_{0}+\mathrm{b}_{1} \mathrm{x}_{1}+\mathrm{b}_{2} \mathrm{x}_{2}+\ldots+\mathrm{b}_{\mathrm{n}} \mathrm{x}_{\mathrm{n}} \\
\mathrm{B}^{\wedge}=\left[\begin{array}{l}
b_{0} \\
b_{1} \\
b_{2}
\end{array}\right]=\left(\mathrm{x}^{1} \mathrm{x}\right)^{-}\left(\mathrm{x}^{1} \mathrm{y}\right)
\end{array}
$$




$$
\left(x^{1} y\right)=\left[\begin{array}{c}
\Sigma y \\
\Sigma x_{1} y \\
\Sigma x_{2} y
\end{array}\right]
$$

Tbl 1. Keterangan Simbol

\begin{tabular}{cc}
\hline Simbol & Parameter \\
\hline Ein & Tegangan Induksi (Volt) \\
$\mathrm{N}$ & Jumlah Lilian \\
$\mathrm{d} \Phi$ & Perubahan Fluks Magnetik (Wb) \\
$\mathrm{dt}$ & Perubahan Waktu (detik) \\
$\mathrm{f}$ & Frekuensi Listrik (Hz) \\
$\mathrm{Nr}$ & Kecepatan Putar Rotor (rpm) \\
$\mathrm{C}$ & Konstanta Mesin \\
$n s$ & Kecepatan Sinkron \\
$\Phi$ & Fluks yang dihasilkan (Wb) \\
Erms & Tegangan Induksi (Volt) \\
$\mathrm{I}$ & Arus (Ampere) \\
$\mathrm{S}$ & Daya Semu (VA) \\
$\mathrm{Ns}$ & Jumlah kumparan \\
$\mathrm{Nph}$ & Jumlah fasa \\
$\mathrm{P}$ & Jumlah Kutub Magnet \\
$\mathrm{Br}$ & Kerapatan Fluks (T) \\
$\mathrm{Lm}$ & Tinggi Magnet (m) \\
$\delta$ & Lebar Celah Udara (m) \\
$\mathrm{Bmax}$ & Fluks Magnet Maksimal (T) \\
$\eta$ & Efisiensi \\
\hline
\end{tabular}

\section{METODE}

\subsection{Diagram Alur Penelitian}

Pada Gbr. 3 merupakan diagram alur yang menjelaskan tahapan penelitian modifikasi motor BLDC menjadi PMSG fluks radial.

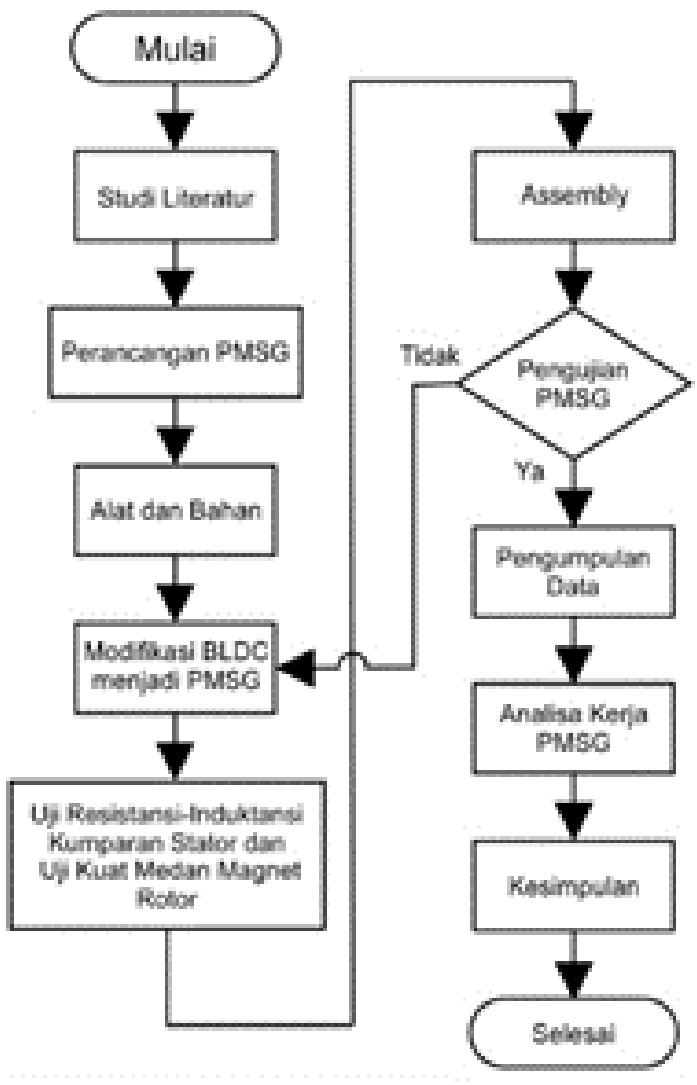

Gbr 3. Diagram Alur Penelitian

\subsection{Blok Diagram Pengujian}

Blok diagram pengujian seperti pada Gbr. 4 menjelaskan tentang cara pengujian PMSG dengan 3 kondisi, diantaranya pengujian short circuit untuk mengetahui reaktansi jangkar, pengujian open circuit untuk mengetahui tegangan yang keluar sesuai dengan kecepatan dan pengujian berbeban untuk mengetahui kapasitas daya PMSG. Beban yang digunakan berupa beban resistif, beban induktif dan beban kapasitif.

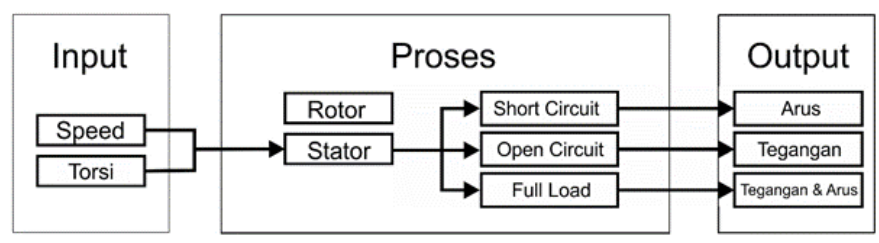

Gbr 4. Blok Diagram Pengujian

\section{HASIL DAN PEMBAHASAN}

4.1 Spesifikasi PMSG Fluks Radial

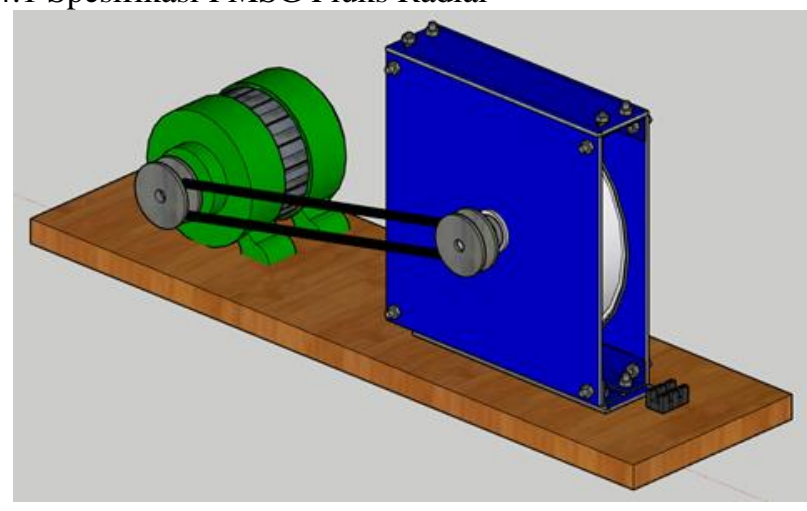

Gbr 5. PMSG Fluk Radial

Tbl 2. Spesifikasi PMSG Fluks Radial

\begin{tabular}{ll}
\hline Slot / Pole & $36 / 24$ \\
\hline Diameter dalam stator & $272 \mathrm{~mm}$ \\
\hline Tebal Stator & $31,5 \mathrm{~mm}$ \\
\hline Spesifikasi kumparan & $0,8 \mathrm{~mm} / 88$ lilitan \\
\hline Diameter rotor & $288 \mathrm{~mm}$ \\
\hline Material magnet & Barium ferrite $(\mathrm{BaO} 6 \mathrm{Fe} 2 \mathrm{O} 3)$ \\
\hline Dimensi magnet & $70 \mathrm{~mm}$ x $32 \mathrm{~mm}$ x 6 mm (12 batang) \\
\hline Celah udara & $1 \mathrm{~mm}$ \\
\hline Kecepatan Putar rotor, $\mathbf{n}_{\mathbf{s}}$ & $1300 \mathrm{RPM}$ \\
\hline Medan magnet relatif, $\mathbf{B}_{\mathbf{r}}$ & $\mathrm{Br}=1,149$ \\
\hline Faktor Belitan, $\mathbf{K}_{\mathbf{w}}$ & 0,95 \\
\hline Tegangan, E & $115-200 \mathrm{VAC}$ \\
\hline Tahanan Jangkar & $4,15 \Omega$ \\
\hline Induktansi Jangkar & $11,11 \mathrm{mH}$ \\
\hline Sudut Mekanik Slot & $8^{\circ}$ \\
\hline Sudut Mekanik Pole & $24^{\circ}$ \\
\hline Daya & $591,66 \mathrm{VA}$ \\
\hline IL & $0,57 \mathrm{~A}$ \\
\hline Kri\% & $97 \%$ \\
\hline B $_{\text {max }}$ & $0,984 \mathrm{~T}$ \\
\hline \multicolumn{1}{c}{ Konstruksi generator yang digunakan merupakan } \\
\hline
\end{tabular}

BLDC motor mesin cuci bekas jenis satu tabung. Modifikasi yang dilakukan hanya pada formasi sambungan antar coil stator tanpa mengganti kawat email, jumlah lilitan ataupun jenis magnet permanen pada rotor.

Perencanaan tegangan kerja generator dimulai dari tegangan drop 115 VAC sampai $200 \mathrm{VAC}$ (fasa - netral). Modifikasi yang dilakukan bertujuan untuk membandingkan 
daya output generator menggunakan formasi kumparan pabrikasi 1 x 12 coil dengan formasi 6 x 2 coil.

\subsection{Frekuensi Elektris}

\begin{tabular}{|c|c|c|c|}
\hline NO & RPM & P (Kutub Magnet) & Frekuensi $(\mathrm{Hz})$ \\
\hline 1 & 250 & \multirow{6}{*}{$24 \mathrm{~N}-\mathrm{S}$} & 50 \\
\hline 2 & 500 & & 100 \\
\hline 3 & 750 & & 150 \\
\hline 4 & 1000 & & 200 \\
\hline 5 & 1250 & & 250 \\
\hline 6 & 1400 & & 280 \\
\hline
\end{tabular}

\subsection{Torsi Generator}

\begin{tabular}{|c|c|c|c|c|}
\hline $\mathrm{NO}$ & RPM (n) & $\omega(\mathrm{rad} / \mathrm{sec})$ & $K t=K e$ & $T(\mathrm{Nm})$ \\
\hline 1 & 250 & 26,17 & \multirow{6}{*}{1,57} & 0,009 \\
\hline 2 & 500 & 52,35 & & 0,172 \\
\hline 3 & 750 & 78,53 & & 0,258 \\
\hline 4 & 1000 & 104,71 & & 0,346 \\
\hline 5 & 1250 & 130,89 & & 0,432 \\
\hline 6 & 1400 & 146,80 & & 0,483 \\
\hline
\end{tabular}

4.3 Pengujian Tanpa Beban Kumparan Pabrikasi 1 x 12C
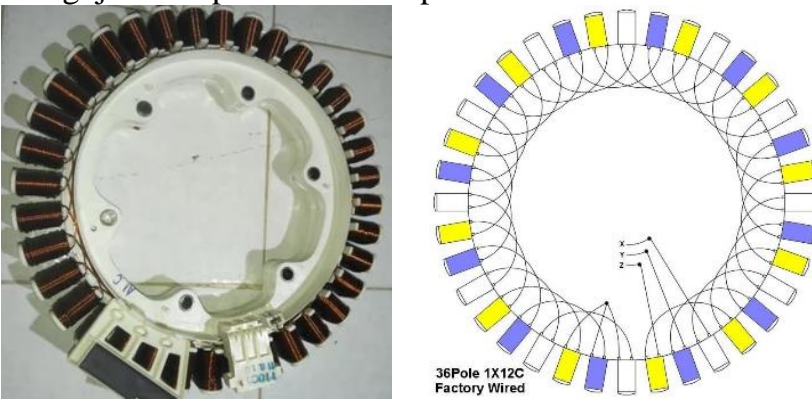

Gbr 6. Kumparan Pabrikasi 1 x 12 C

Hasil pengujian tanpa beban tegangan fasa-netral kumparan pabrikasi 1 x $12 \mathrm{C}$

\begin{tabular}{|c|c|c|c|}
\hline \multicolumn{4}{|c|}{$y=0,0000 x^{2}+0,1602 x-0,4624$} \\
\hline No & $\begin{array}{c}\text { Kecepatan } \\
\text { (RPM) }\end{array}$ & $\begin{array}{c}\text { Tegangan } \\
\text { hasil uji (V) }\end{array}$ & $\begin{array}{l}\text { Tegangan estimasi } \\
\text { (V) }\end{array}$ \\
\hline 1 & 135 & - & 21.2284 \\
\hline 2 & 250 & 39.4 & 39.8104 \\
\hline 3 & 500 & 82.3 & 80.538 \\
\hline 4 & 750 & 119.1 & 121.7204 \\
\hline 5 & 1000 & 164.7 & 163.3577 \\
\hline 6 & 1250 & 205.8 & 205.4499 \\
\hline 7 & 1400 & 230.5 & 230.9235 \\
\hline 8 & 1500 & - & 250.5642 \\
\hline 9 & 1750 & - & 279.8876 \\
\hline 10 & 2000 & - & 319.9376 \\
\hline
\end{tabular}

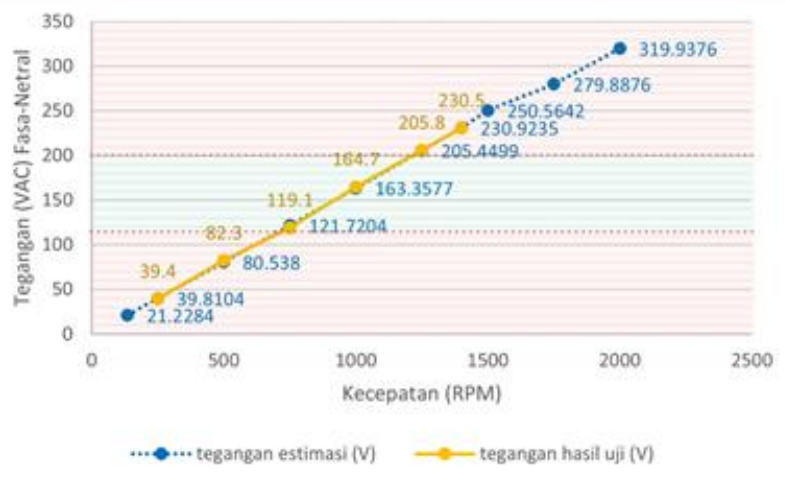

Gbr 7. Grafik Tegangan Fasa-Netral Kumparan 1 x 12C

Hasil pengujian tanpa beban tegangan fasa-fasa kumparan pabrikasi 1 x $12 \mathrm{C}$.

Tbl 5. Tegangan Fasa-Fasa Kumparan $1 \times 12 \mathrm{C}$

\begin{tabular}{cccc}
\hline \multicolumn{4}{c}{$\mathbf{y = 0 , 0 0 0 0 \mathbf { x } ^ { 2 } + \mathbf { 0 , 2 6 3 7 } \mathbf { x } + \mathbf { 1 , 5 1 2 8 }}$} \\
\hline \multirow{2}{*}{ No } & $\begin{array}{c}\text { Kecepatan } \\
\text { (RPM) }\end{array}$ & $\begin{array}{c}\text { Tegangan } \\
\text { hasil uji }(\mathbf{V})\end{array}$ & $\begin{array}{c}\text { Tegangan estimasi } \\
(\mathbf{V})\end{array}$ \\
\hline 1 & 135 & - & 37.3378 \\
2 & 250 & 67.4 & 68.2031 \\
3 & 500 & 140.5 & 136.4051 \\
4 & 750 & 199.6 & 206.1187 \\
5 & 1000 & 280.8 & 277.3439 \\
6 & 1250 & 351 & 350.0808 \\
7 & 1400 & 393.1 & 394.4484 \\
8 & 1500 & - & 428.8322 \\
9 & 1750 & - & 459.9622 \\
10 & 2000 & - & 525.8872 \\
\hline
\end{tabular}

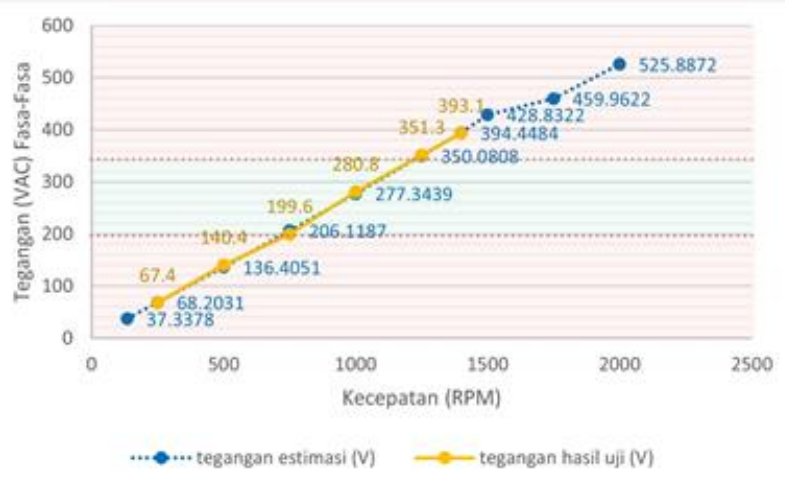

Gbr 8. Grafik Tegangan Fasa-Fasa Kumparan 1 x 12C

Pada gambar 7 dan 8 daerah yang berwarna biru adalah daerah rencana kerja PMSG dari tegangan 115V-200V AC. 4.4 Pengujian Tanpa Beban Kumparan Modifikasi 6 x 2C
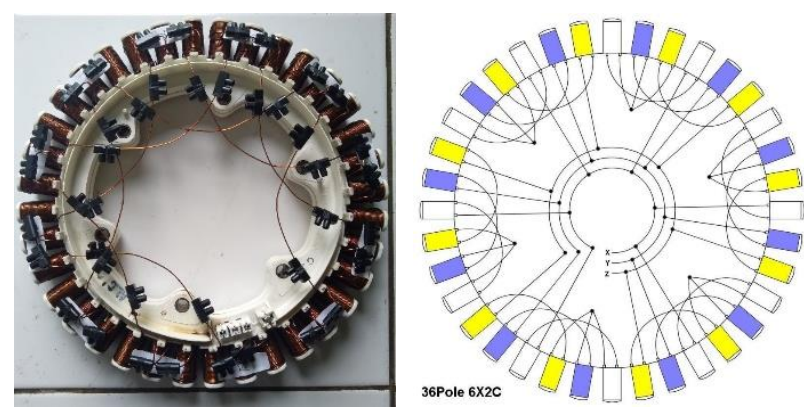

Gbr 9.

Kumparan Modifikasi 6 × 2 C 
Tbl 6. Tegangan Fasa-Netral Kumparan 6 x 2 C

\begin{tabular}{cccc}
\hline \multicolumn{4}{c}{$\mathbf{Y = 0 . 0 0 0 0 \mathbf { x } ^ { 2 } + \mathbf { 0 . 0 2 4 6 x } + \mathbf { 0 . 2 1 8 8 }}$} \\
\hline No & $\begin{array}{c}\text { Kecepatan } \\
(\mathbf{R P M})\end{array}$ & $\begin{array}{c}\text { Tegangan } \\
\text { hasil uji (V) }\end{array}$ & $\begin{array}{c}\text { Tegangan estimasi } \\
(\mathbf{V})\end{array}$ \\
\hline 1 & 135 & - & 3.5466 \\
2 & 250 & 6.4 & 6.3975 \\
3 & 500 & 12.7 & 12.6463 \\
4 & 750 & 18.8 & 18.9653 \\
5 & 1000 & 25.5 & 25.3544 \\
6 & 1250 & 31.8 & 31.8137 \\
7 & 1400 & 35.7 & 35.7229 \\
8 & 1500 & - & 38.7371 \\
9 & 1750 & - & 42.8312 \\
10 & 2000 & - & 48.9812 \\
\hline
\end{tabular}

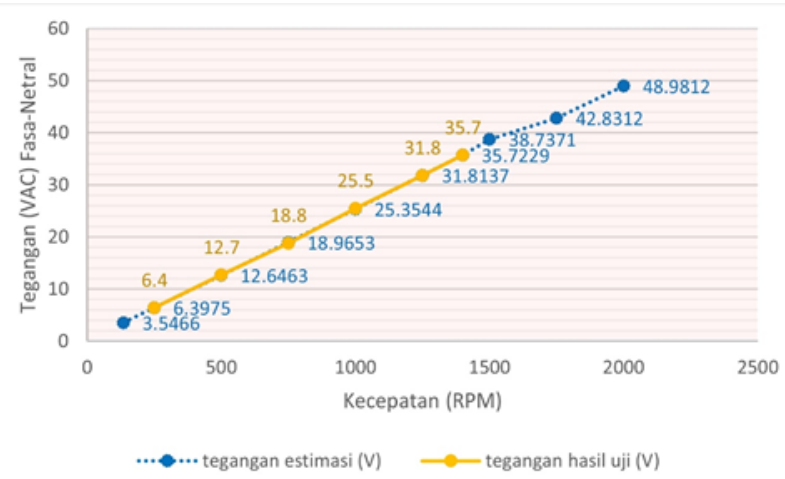

Gbr 10. Grafik Tegangan Fasa-Netral Kumparan 6 x 2C

Hasil pengujian tanpa beban tegangan fasa-fasa kumparan pabrikasi 6 × $2 \mathrm{C}$.

\begin{tabular}{|c|c|c|c|}
\hline \multicolumn{4}{|c|}{$Y=0.0000 x^{2}+0.0415 x+0.9047$} \\
\hline No & $\begin{array}{c}\text { Kecepatan } \\
\text { (RPM) }\end{array}$ & $\begin{array}{c}\text { Tegangan } \\
\text { hasil uji (V) }\end{array}$ & $\begin{array}{c}\text { Tegangan estimasi } \\
\text { (V) }\end{array}$ \\
\hline 1 & 135 & & 6.55 \\
\hline 2 & 250 & 11.4 & 11.4186 \\
\hline 3 & 500 & 22.5 & 22.1917 \\
\hline 4 & 750 & 32.5 & 33.2237 \\
\hline 5 & 1000 & 45 & 44.5148 \\
\hline 6 & 1250 & 56.2 & 56.0649 \\
\hline 7 & 1400 & 62.933 & 63.1193 \\
\hline 8 & 1500 & - & 68.5908 \\
\hline 9 & 1750 & - & 71.7203 \\
\hline 10 & 2000 & - & 82.0953 \\
\hline
\end{tabular}

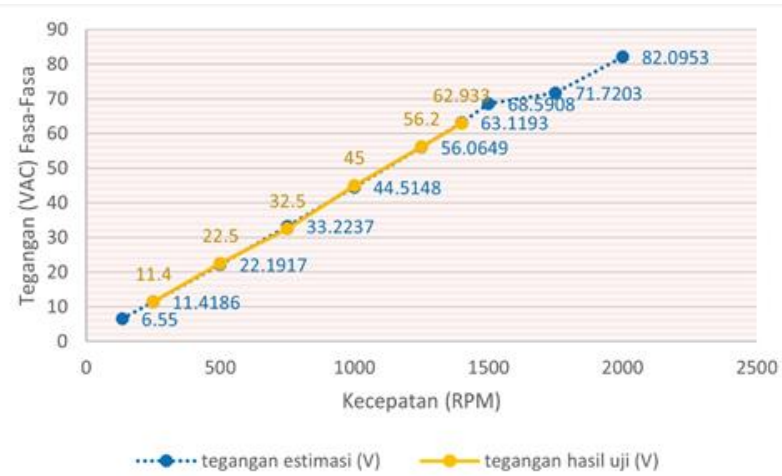

Gbr 11. Grafik Tegangan Fasa-Fasa Kumparan 6 x 2C

Pada percobaan tegangan tanpa beban kumparan yang telah dimodifikasi $6 \times 2 \mathrm{C}$, tegangannya turun setengah dari tegangan kerja ketika kumparan berformasi 1 x 12C. Hal ini disebabkan karena jumlah kutub magnet yang tidak sesuai dengan rancangan optimal generator. Karena tidak merubah atau mengganti jenis magnet rotor maka pada pengujian berbeban menggunakan formasi 1 x $12 \mathrm{C}$.

4.5 Pengujian Short Circuit

\begin{tabular}{|c|c|c|}
\hline \multicolumn{3}{|c|}{ Arus Jangkar (Ampere) } \\
\hline Fasa $R$ - Fasa $S$ & Fasa $S-$ Fasa $T$ & Fasa $T$ - Fasa $R$ \\
\hline $2,58 \mathrm{~A}$ & $2,56 \mathrm{~A}$ & $2,59 \mathrm{~A}$ \\
\hline
\end{tabular}

Pengujian dilakukan pada kecepatan rendah 300 RPM.

4.6 Pengujian Beban Resistif

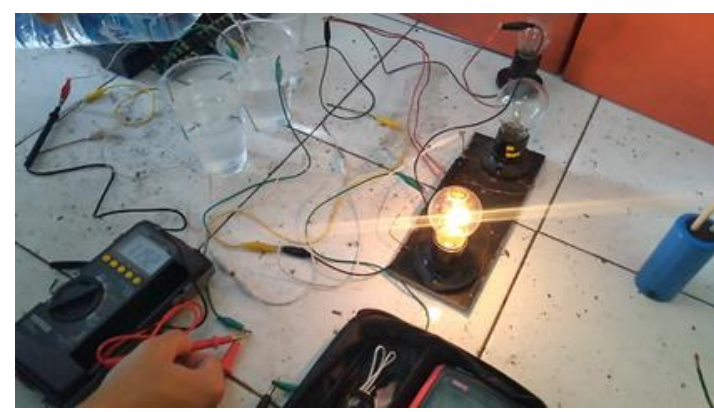

Gbr 12. Pengujian Beban Resistif

Tb1 9. Grafik Beban Resistif

\begin{tabular}{cccc}
\hline Percobaan ke - & $\begin{array}{c}\text { Tegangan } \\
\text { (VAC) }\end{array}$ & Arus (mA) & $\begin{array}{c}\text { Hambatan } \\
\text { (KS) }\end{array}$ \\
\hline $\mathbf{1}$ & 115 & 0.1255 & 1.197 \\
\hline $\mathbf{2}$ & 120 & 0.1279 & 1.19 \\
\hline $\mathbf{3}$ & 125 & 0.1303 & 1.176 \\
\hline $\mathbf{4}$ & 130 & 0.1327 & 1.163 \\
\hline $\mathbf{5}$ & 135 & 0.1351 & 1.149 \\
\hline $\mathbf{6}$ & 140 & 0.1375 & 1.134 \\
\hline $\mathbf{7}$ & 145 & 0.1399 & 1.119 \\
\hline $\mathbf{8}$ & 150 & 0.1423 & 1.104 \\
\hline $\mathbf{9}$ & 155 & 0.1447 & 1.088 \\
\hline $\mathbf{1 0}$ & 160 & 0.1471 & 1.071 \\
\hline $\mathbf{1 1}$ & 165 & 0.1495 & 1.054 \\
\hline $\mathbf{1 2}$ & 170 & 0.1519 & 1.036 \\
\hline $\mathbf{1 3}$ & 175 & 0.1543 & 1.018 \\
\hline $\mathbf{1 4}$ & 180 & 0.1567 & 0.999 \\
\hline $\mathbf{1 5}$ & 185 & 0.1591 & 0.98 \\
\hline $\mathbf{1 6}$ & 190 & 0.1615 & 0.959 \\
\hline $\mathbf{1 7}$ & 195 & 0.1639 & 0.938 \\
\hline $\mathbf{1 8}$ & 200 & 0.1671 & 0.916 \\
\hline
\end{tabular}

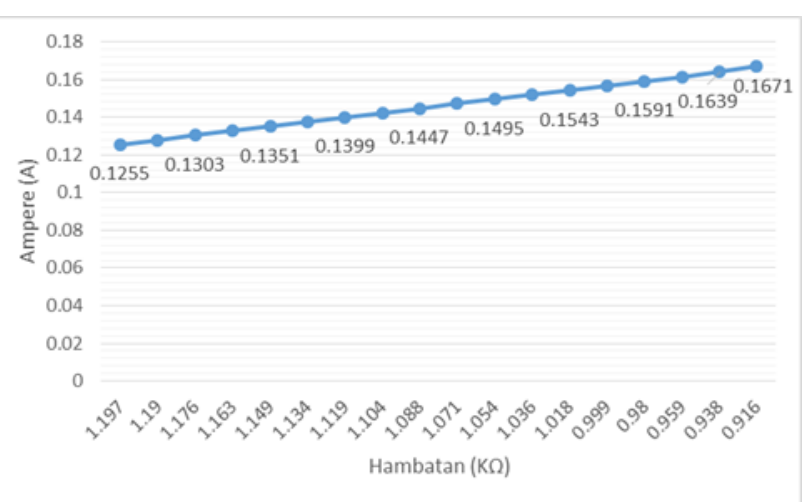

Gbr 13. Grafik Arus Beban Resistif 


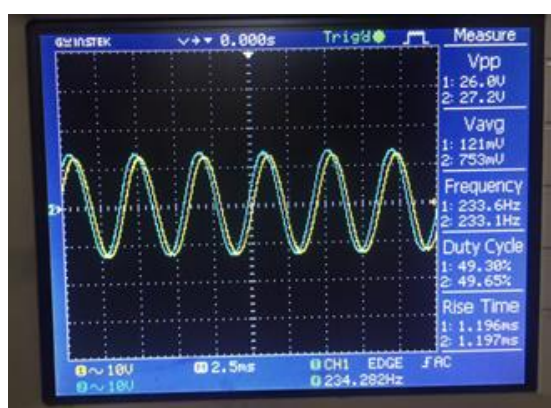

Gbr 14. Gelombang Beban Resistif

\subsection{Pengujian Beban Induktif}

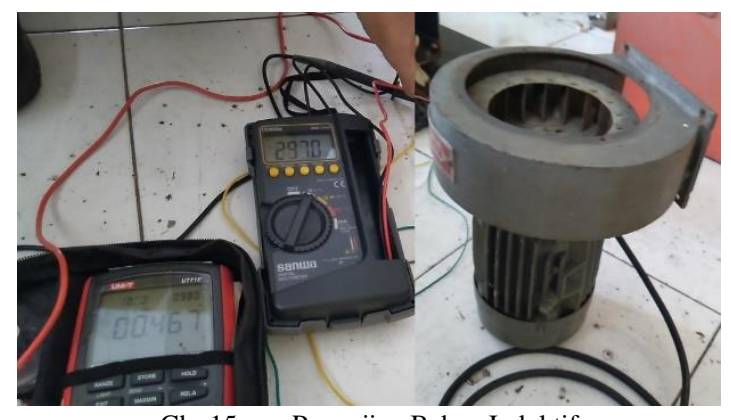

Gbr 15. Pengujian Beban Induktif

\begin{tabular}{cccccc}
\multicolumn{4}{c}{ Tbl 10. } & \multicolumn{2}{c}{ Beban Induktif } \\
\hline \multicolumn{3}{c}{$\begin{array}{c}\text { Tegangan Antar Fasa } \\
\text { (V AC) }\end{array}$} & \multicolumn{4}{c}{ Arus antar Fasa (A) } \\
\hline R-S & S-T & T-R & R-S & S-T & T-R \\
\hline $\mathbf{2 9 6 , 8}$ & $\mathbf{2 9 6 , 3}$ & $\mathbf{2 9 6 , 1}$ & $\mathbf{0 , 4 7 8}$ & $\mathbf{0 , 4 7 4}$ & $\mathbf{0 , 4 7 1}$ \\
\hline
\end{tabular}

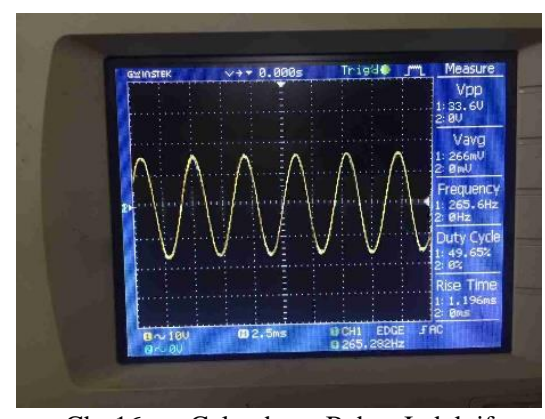

Gbr 16. Gelombang Beban Induktif

4.8 Pengujian Beban Kapasitif

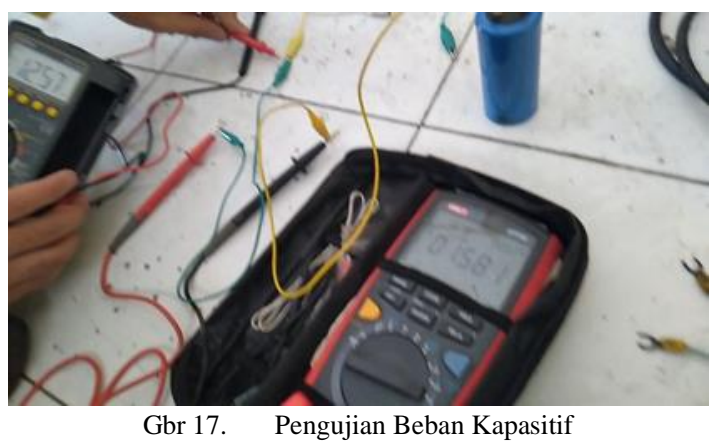

Tbl 11. Beban Kapasitif

\begin{tabular}{cccccc}
\hline \multicolumn{2}{c}{ Tegangan Tiap Fasa (V AC) } & \multicolumn{3}{c}{ Arus Tiap Fasa (A) } \\
\hline Fasa R & Fasa S & Fasa T & Fasa R & Fasa S & Fasa T \\
\hline 125,8 & 125,4 & 125,6 & 1,64 & 1,60 & 1,62 \\
\hline
\end{tabular}

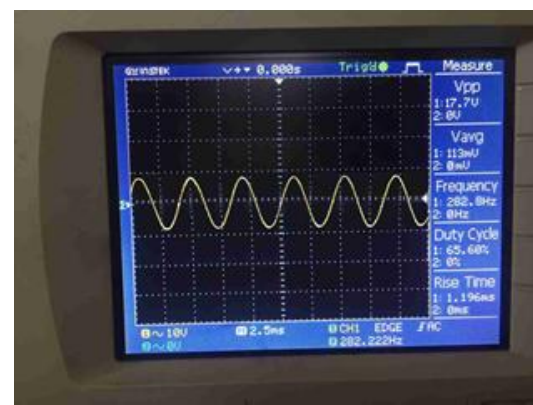

Gbr 18. Gelombang Beban Kapasitif

4.9 Analisa Daya Masuk dan Daya Keluar

1. Beban Resistif Pin $=33,4 \mathrm{~W}$; Pout $=19,2 \mathrm{~W}$

2. Beban Kapasitif Pin $=325 \mathrm{~W}$; Pout $=203,1$ W

3. Beban Induktif Pin $=205,6$; Pout $=104,4 \mathrm{~W}$

\subsection{Efisiensi}

1. Beban Resistif $=57,4 \%$

2. Beban Kapasitif $=62,4 \%$

3. Beban Induktif $=68,2 \%$

\section{KESIMPULAN}

Berdasarkan hasil penelitian dan pembahasan, kumparan pabrikasi 1 x $12 \mathrm{C}$ memiliki daya yang besar dibandingkan dengan kumparan yang dimodifikasi $6 \times 2 \mathrm{C}$ karena jumlah kutub magnet pada rotor tidak sesuai dengan rancangan optimal generator. Perubahan jenis atau jumlah magnet pada rotor akan menambah biaya besar. Oleh karena itu modifikasi pada generator tidak layak pada pengujian berbeban.

Pengujian berbeban memiliki rentang tegangan kerja, dimulai dari 115 - 200 VAC. Beban yang digunakan ada 3 jenis, yaitu beban resistif, beban kapasitif dan beban induktif. Pada beban resistif generator diuji sampai tegangan drop $115 \mathrm{~V}$ menghasilkan tegangan regulasi sebesar $78,9 \%$. Pada beban kapasitif tegangan drop sampai $125,6 \mathrm{~V}$ menghasilkan tegangan regulasi sebesar $59,2 \%$ dan pada beban induktif tegangan drop sampai 296,2V menghasilkan tegangan regulasi sebesar $18,2 \%$.

\section{REFERENSI}

[1] Pudji Irasari, Muhammad Kasim, Fitriana. Optimasi Kemiringan Magnet Pada Generator Magnet Permanen Kecepatan Rendah Fluks Radial. Bandung : LIPI

[2] Pramono, Gatot Eka, Fithri Muliawati, and Nur Fajri Kurniawan. 2017. "DESAIN DAN UJI KINERJA GENERATOR AC FLUKS RADIAL MENGGUNAKAN 12 BUAH MAGNET PERMANEN TIPE NEODYMIUM (NdFeB) SEBAGAI PEMBANGKIT LISTRIK." Juteks 4: 34-40.

[3] Jearl Walker. (2014). Fundamentals of Physics Halliday \& resnick 10ed. In Wiley.

[4] Fitriyani Hayono, Yukiana. 2020. “Aplikasi Perancangan Generator Sinkron Magnet Permanen Pada Pembangkit." 
[5] Andika, \& Hamzah, A. (2018). Perancangan dan Pembuatan Generator Fluks Radial Tiga Fasa Magnet Permanen Kecepatan Rendah. Universitas Riau, 5(1), 1-8.

[6] Fitrianda, M. I. (2013). Digital Digital Repository Universitas Universitas Jember Jember Digital Digital Repository Repository Universitas Universitas Jember.

[7] Hariyotejo, P. (2009). Pengembangan Generator Mini Dengan Menggunakan Magnet Permanen. 1-9.

[8] Indriani, A. (2015). Analisis Pengaruh Variasi Jumlah Kutub dan Jarak Celah Magnet Rotor Terhadap Performan Generator Sinkron Fluks Radial. Jurnal Rekayasa Dan Teknologi Elektro, 9(2).

[9] Marsudi, D. (2016). Politeknik Negeri Sriwijaya 4. Pembangkitan Energi Listrik, 7(1), 4-31.
[10] National Import LLC. (2017). Permanent Magnet Selection and Design Handbook.

[11] Nuryadi, S. (2013). Tegangan Dan Efisiensi Daya Pada Perancangan Generator Magnet Permanen Menggunakan Software Magnet.

\section{BIOGRAFI PENULIS}

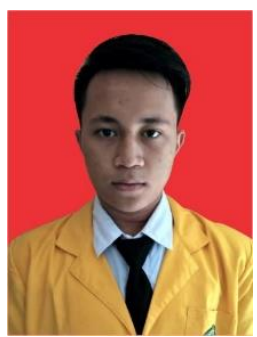

Dhea Gemilang Ramdhany, saya lahir di Majalengka pada tanggal 27 Januari 1997, saya kuliah di jurusan Teknik Elektro Universitas Siliwangi, konsentrasi penelitian saya yaitu Modifikasi Motor Brushless DC Menjadi Generator Sinkron Magnet Permanen Fluks Radial Putaran Rendah. 